\title{
Causes of Respiratory Ailments in Pregnancy
}

\author{
T. Sroczynski1 ${ }^{1}$ A. Gawlikowska-Sroka², E. Dzieciolowska-Baran² ${ }^{2}$ I. Poziomkowska-Gesicka ${ }^{3}$ \\ ${ }^{1}$ Department of Physiology, Pomeranian Medical University, Szczecin, Poland; \\ ${ }^{2}$ Department of Normal and Clinical Anatomy, Pomeranian Medical University, Szczecin, Poland; \\ ${ }^{3}$ Department of Clinical Allergology, Pomeranian Medical University, Szczecin, Poland
}

\begin{abstract}
Objective: During pregnancy, especially during its third trimester, most pregnant women reported respiratory discomfort (dyspnea), despite the absence of previously coexisting respiratory illnesses. The aim of this study was to determine the reason for this discomfort. Material and methods: The study included 24 women examined before and after childbirth. Evaluation of respiratory complains was made on the basis of the respiratory questionnaire of St. George's Hospital. The data were correlated with the results of static and dynamic spirometric tests performed before and after childbirth.

Results: Pregnancy did not affect vital capacity (VC). Frequency of perceived symptoms correlated positively with IRV and the ratio IC/VC. A negative correlation was found between ERV and its derivative ERV/VC. There was no relationship between perceived discomfort and parameters of the flow-volume loop.

Conclusions: The extent of perceived respiratory discomfort (dyspnea) during pregnancy was primarily associated with a reduction in expiratory reserve (ERV).
\end{abstract}

Key words: pregnancy, respiratory symptoms, spirometry

\section{INTRODUCTION}

Pregnancy affects the physiology of respiration by changing the parameters of the chest, and the course of diseases of the respiratory system [1-4]. Most pregnant women report periodically occurring breathing difficulties and even dyspneic symptoms, despite the lack of previously recorded or co-existing with pregnancy respiratory illnesses. These problems may result from hypoxia, changes in respiratory mechanics [5-7] and the sensitivity of the respiratory complex of the brain stem $[8,9]$. The mechanics of respiration, dependent on the function of respiratory muscle, are significantly affected by the quality of nutrition [10, 11]. Pregnant women usually breathe slower and deeper in relation to non-pregnant ones, using, during their quiet breathing, some part of the expiratory reserve volume. Natural myorelaxant factors, acting on bronchi, increase the tendency of the airway to collapse, elevating closing volume [7]. These phenomena may decrease the oxygen saturation in the plasma of blood and thus elicit the perception of dyspnea. Symptoms of respiratory discomfort may, therefore, result from changes in both respiratory mechanics and the tone of bronchi resulting from the action of gestational hormones and other factors observed during pregnancy. The aim of this study was to determine the reasons for respiratory complaints in pregnancy.

\section{Material And Methods}

The study was performed in accord with the Declaration of Helsinki for Human Research and the study protocol was approved by an institutional Ethics Committee.

The study sample consisted of 24 women in single pregnancies. The age of tested pregnant women ranged from 17 to 32 years ( $26 \pm 3$ years). Body height ranged from 150 to $178 \mathrm{~cm}(164 \pm 6 \mathrm{~cm})$ and body mass from 50.6 to $99.5 \mathrm{~kg}(71.9 \pm(10.4 \mathrm{~kg})$ Since smoking cigarettes, pipes, or hookah pipes accelerates the process of aging of the lungs and lowers spirometric indices, only pregnant non-smoking women took part in the study $[5,12,13]$

Spirometry was carried out first in $37.7 \pm 1.2$ week of pregnancy, $13 \pm 4$ days before delivery, and then repeated approximately $39 \pm 12$ days after delivery (the mean interval between the first and second measurement was $55 \pm 11$ days). The applied test method used a Lungtest 1000 pneumotachograph spirometer (MES, Cracow, Poland). Ambient temperature, pressure and humidity were measured by the measuring device Oregon Scientific Model BA 888, which allowed the recording of the research results in conditions of BPTS. Spirometry was performed in the standard way, following regimes recommended by the European Respiratory Society [14, 15]. All women were seating during the test. Spirometry took from 20 to $40 \mathrm{~min}$ and consisted of three stages: (1) static components of the vital capacity, (2) the dynamic parameters of forceful inspiration and expiration in the whole range of the forced vital capacity, including assessment of the flow-volume loop and volume-time curve, and (3) maximum voluntary ventilation with assessment of the breathing reserve.

Respiratory symptoms were assessed according to the questions of the St. George's Hospital questionnaire [16], before the spirometric tests. Part I of the questionnaire included questions concerning symp- 
toms of respiratory disease and their severity. Every answer confirming the presence of particular symptom was scored, depending on its severity, from 1 to 4 points. In the case of absence of particular symptoms no points were given. In part II we assessed the situations in which respiratory symptoms are felt.

In the descriptive analysis of results, the following were used: the arithmetical mean $-\overline{\mathrm{x}}$, median $-\mathrm{Me}$, range of values, and standard deviation - SD. Normality of distribution of the reported results was examined using the Kolmogorov-Smirnov test with the Lilliefors amendment. The hypothesis of the homogeneity of the variance of compared parameters was verified by Levene's test. To assess the significance of differences in cases where the distribution of the collected parameters was normal we used: a parametric t-test for small groups $(n \leq 30)$ for homogeneous variances of paired variables, and the Cochran-Cox parametric test. In cases where the Kolmogorov-Smirnov test with the Lilliefors amendment did not confirm the hypothesis of the normal distribution of variables, nonparametric tests were used: the Wilcoxon matchedpairs test for related variables and the Mann-Whitney $\mathrm{U}$ test for unrelated variables. In assessing the relationship between measured parameters and respiratory symptoms, Spearman's rank correlation coefficient was used. To assess the statistical significance, the level of significance $\mathrm{P}<0.05$ was used.

\section{RESULTS}

Most pregnant women reported respiratory symptoms despite the lack of co-existing respiratory illnesses in their personal case histories. The intensity of complaints was mild. More than half of the respondents reported the presence of occasional cough. One third of the women reported the presence of dyspnea, and most of them suffered because of fatigue. Respiratory discomfort was induced by fast walking, climbing stairs, or even performing household activities. Most respondents reported that standard daily activities take more time than usual and require longer rest. It was noted that symptoms intensified after entering smoky rooms. None of the women surveyed in pregnancy reported respiratory ailments after childbirth.

Spirometric examination did not reveal significant functional changes in vital capacity (VC) after delivery compared with that before it (Fig. 1). Significant changes

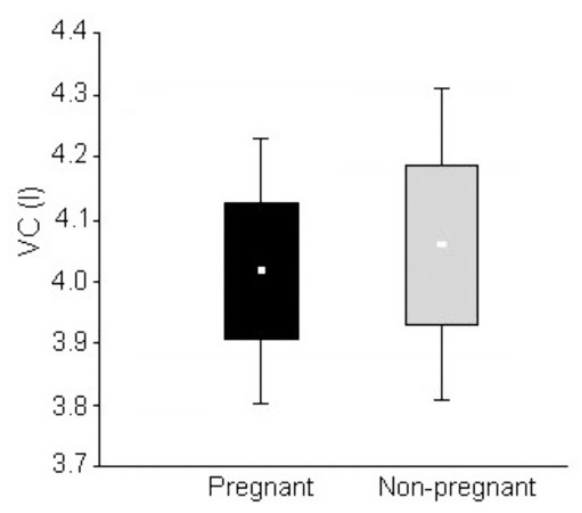

Fig. 1. Vital capacity before $v$ s. after delivery.

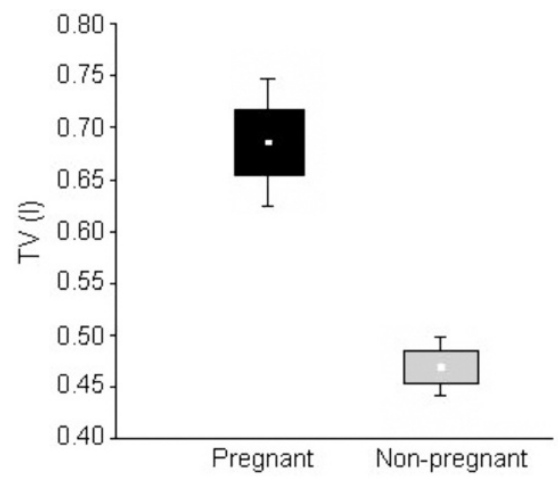

Fig. 2. Tidal volume before $v$ s. after delivery.

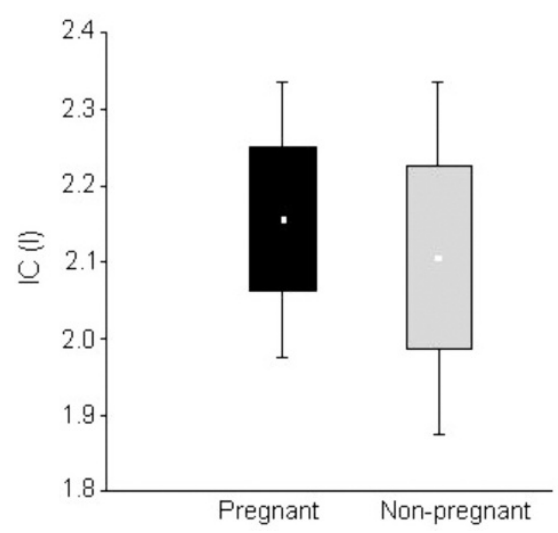

Fig. 3. Inspiratory capacity before $v$ s. after delivery.

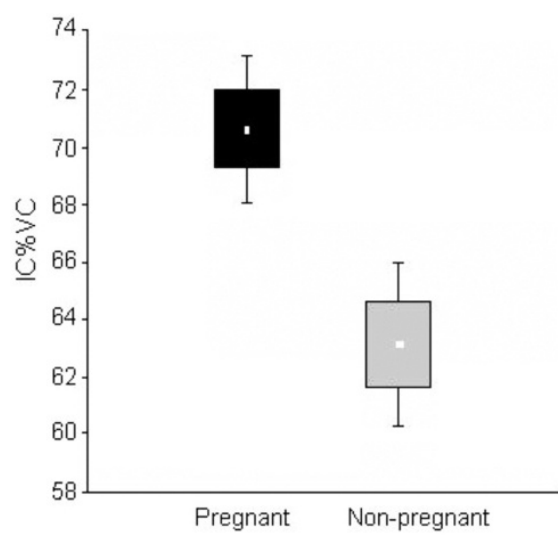

Fig. 4. Inspiratory capacity as a fraction (x100) of vital capacity before $v s$. after delivery.

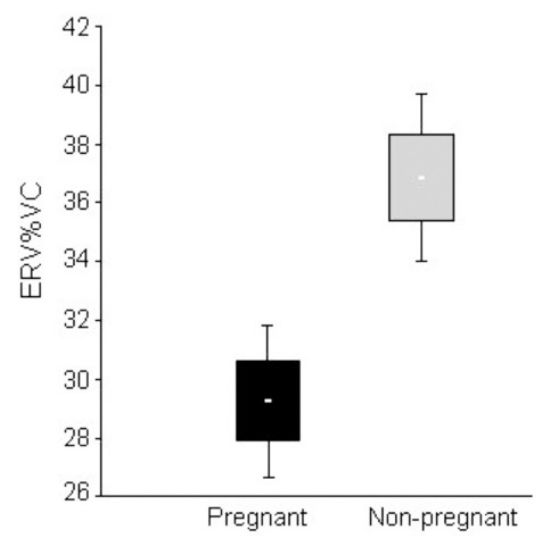

Fig. 5. Expiratory reserve volume as a fraction (x100) of vital capacity before $v s$. after delivery. 


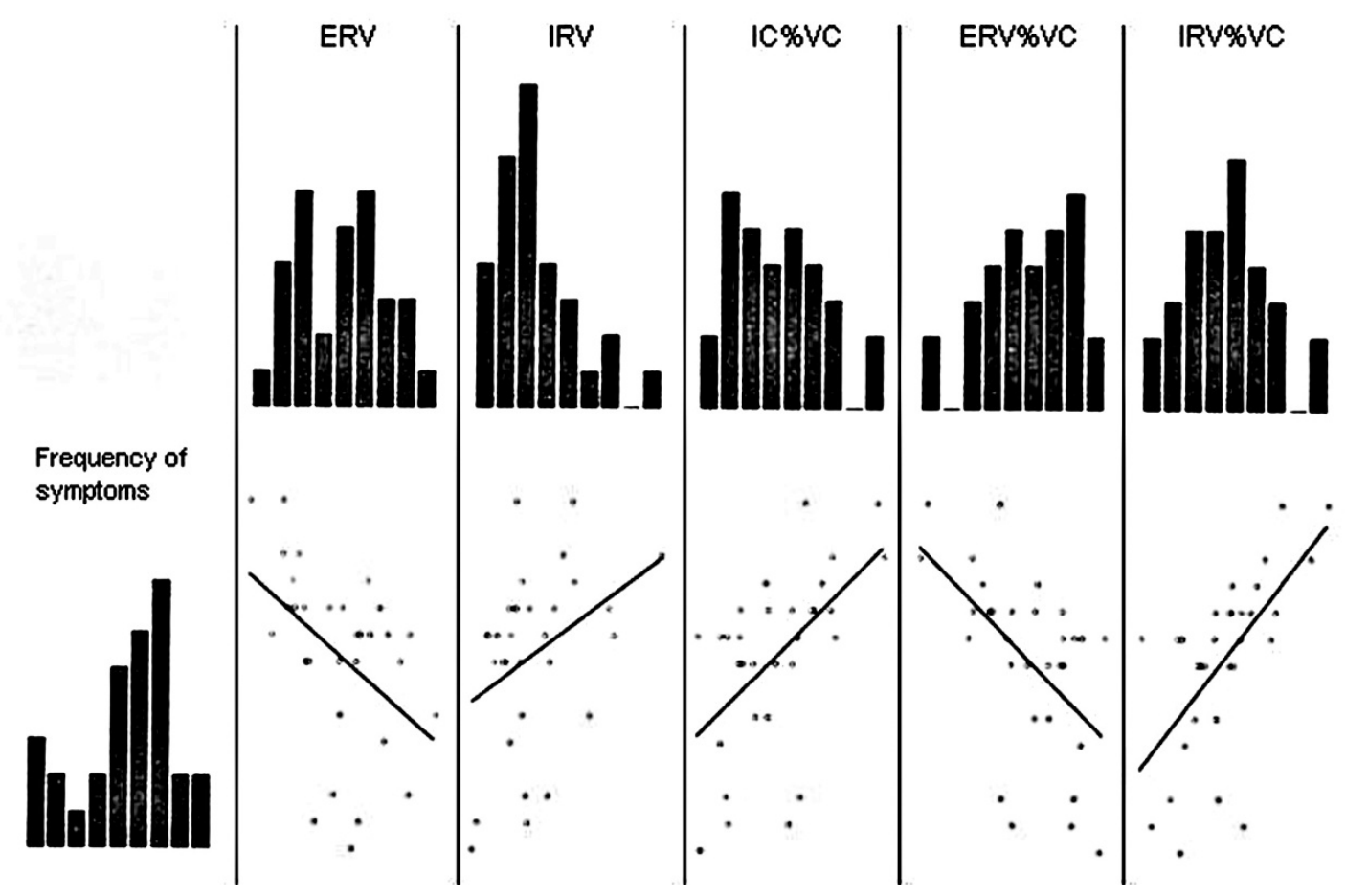

Fig. 6. Associations between the frequency of respiratory symptoms and changes in spirometric indices in pregnant women.

were observed in the measurements of tidal volume (TV), inspiratory capacity (IC), and expiratory reserve volume (ERV) (Figs. 2-5). Comparing data obtained from the questionnaire with the spirometric results, a positive correlation was found between the respiratory symptoms and tidal volume (TV), forced inspiratory time (FIT), value of diastolic blood pressure and pulse rate measured before the spirometric test. Parameter TPIF/FIT correlated negatively. A number of cases, where respiratory symptoms were clearly perceived, correlated with IRV, expressed in both absolute values and percentage of the vital capacity (IRV/VC). A similar relationship was noticed in IC/VC. Equally high, but negative, was the correlation between ERV and its derivative ERV/VC with the occurrence of symptoms (Fig. 6).

\section{Discussion}

The present study confirmed that pregnancy did not affect VC, assessed in static spirometry. However, TV increased, IRV remained unchanged, and ERV declined. The enlarged volume of TV appearing in pregnant women may be associated with greater mobilization of respiratory muscles. Similar observations were obtained by Das et al [17], Puranik et al [18], and Kolarzyk et al [10]. Reductions in $\mathrm{FVC}_{\mathrm{EX}}$ were noted by Mokkapatti et al [19]. Shifting of air volume among components of VC is mainly due to the restricted respiratory mobility of the diaphragm moved upward by the enlarging uterus. This leads to a reduction in the longitudinal dimension of the chest and the compensatory enlargement of the antero-posterior and transverse dimension of the thorax, accompanied by the increase of the costal angle [20, 21].

There was no relationship between perceived discomfort and the parameters of the flow-volume loop.
The range of perceived problems was instead associated with a reduction in ERV during normal resting breathing, with normal parameters of forced ventilation. The correlation analysis of collected material shows that reduced ERV could be a reason quoted often in pregnant women's respiratory discomfort. Similar distributions of observed spirometry values were noted by Ziora et al [11] in women suffering because of anorexia nervosa, and that was associated with fatigue of the respiratory muscles.

Significant roles in respiratory efficiency are expected from such parameters as $\mathrm{FEV}_{1}$ and PEF, which are of great importance in the assessment of the state of airways and the strength of respiratory muscles. $\mathrm{FEV}_{2}$ and $\mathrm{FEV}_{3}$ reflect the state of distal bronchi. Das et al [17] observed no changes in $\mathrm{FEV}_{1}$ and PEF, and Mokkapatti et al [19] noted a statistically insignificant decrease in these parameters. In our study the values of $\mathrm{FEV}_{1}, \mathrm{PEF}, \mathrm{MEF}$ and FEF recorded before and after childbirth were similar, while $\mathrm{FEV}_{0.5}$ and $\mathrm{FEV}_{3}$, were significantly lower than expected. Values of $\mathrm{FEV}_{1}$ expressed as a percentage of FVC were lower due to larger than expected FVC. The values of $\mathrm{MEF}_{25}, \mathrm{FEF}_{25 / 75}$ and derivatives - MEF expressed in relation to FVC, were lower than expected. Other values did not differ. Deeper analysis of the flow-volume loop revealed significant differences. Duration of forced expiration FET in the last month of pregnancy was significantly shorter than after birth, as described above, which, in the absence of differences in expiratory flow rates and the lack of difference in $\mathrm{FVC}_{\mathrm{EX}}$, indicates a notable improvement in the efficiency of forceful ventilation. The same forced vital capacity is exhaled by pregnant women faster, and mid-expiratory flows (MEF) are higher. 
A large surface area under the curve (AEX) usually accompanies high respiratory efficiency and greater physical activity. Its positive correlation with respiratory symptoms could be related to the fact that pregnant women who are young, healthy, and adapted to physical activity realize their limitations. Higher diastolic blood pressure and heart rate, parameters not directly related to respiratory efficiency, could indicate extrarespiratory reasons for occurring symptoms [4, 9]. Knuttgen and Emmerson [22] and Kociecki [23] found no changes in frequency of resting ventilation. In our study, as in that of Alaily and Carroll [24], reduced frequency of breathing is observed. A reduction of breathing frequency coinciding with deeper breathing is a mechanism compensating for changes in the mechanics of ventilation.

We conclude that respiratory ailments reported by pregnant women are mostly associated with changes in the components of vital capacity, and do not result from changes in the diameter of the bronchial tree.

Conflicts of interest: No conflicts of interests were declared by the authors in relation to this article.

\section{REFERENCES}

1. Beckmann CA. Peak flow values by gestation in women with asthma. Clin Nurs Res 2008; 17: 174-81.

2. Dombrowski MP. Asthma and pregnancy. Obstet Gynecol 2006; 108: 667-81

3. Juniper EF, Daniel EE, Roberts RS, Kline PA, Hargreave FE, Newhouse MT. Improvement in airway responsiveness and asthma severity during pregnancy. A prospective study. Am Rev Respir Dis 1989; 140: 924-31.

4. Schatz M, Dombrowski MP, Wise R, Momirova V, Landon M, Mabie W, Newman RB, Rouse DJ, Lindheimer M, Miodovnik M, Caritis SN, Leveno KJ, Meis P, Wapner RJ, Paul RH, O'Sullivan MJ, Varner MW, Thurnau GR, Conway DL. Spirometry is related to perinatal outcomes in pregnant women with asthma. Am J Obstet Gynecol 2006: 194: 120-6.

5. Das TK, Moutquin JM, Lindsay C, Parent JG, Fraser W. Effects of smoking cessation on maternal airway function and birth weight. Obstet Gynecol 1998; 92: 201-5.

6. Sliwinski P. Function of the respiratory muscles. Pneumonol Alergol Pol 1996; 64: 697-709.

7. Weinberger SE, Welse ST, Cohen WR, Johnson TS. State of the Art: Pregnancy and the lung. Am Rev Respir Dis 1980; 121: 559-81.

8. Gee JB, Packer BS, Millen JE, Robin ED. Pulmonary mechanics during pregnancy. J Clin Invest 1967; 46: 945-52.

9. Amador-Licona N, Guízar-Mendoza JM, Juárez M, Linares-Segovia B. Heart sympathetic activity and pulmonary function in obese pregnant women. Acta Obstet Gynecol Scand 2009; 88: 314-9.
10. Kolarzyk E, Szot WM, Lyszczarz J. Lung function and breathing regulation parameters during pregnancy. Arch Gynecol Obstet 2005; 272: 53-8.

11. Ziora K, Ziora D, Oswiecimska J, Roczniak W, Machura E, Dworniczak S, Tomalak W, Dyduch A. Spirometric parameters in malnourished girls with anorexia nervosa. J Physiol Pharmacol 2008; 59 Suppl 6: 801-7.

12. Ben Saad H, Khemiss M, Bougmiza I, Prefaut C, Aouina H, Mrizek N, Garrouche A, Zbidi A, Tabka Z. Spirometric profile of narghile smokers. Rev Mal Respir 2009; 26: 299-314 (Article in French).

13. Sroczynski T. Pulmonary function during the last month of normal pregnancy. Ann Acad Med Stetin 2002; 48: 331-50.

14. Quanjer PH. Standardization of lung function tests 1993 update. Report working for the European Community for Steel and Coal. Eur Respir J 1993; 6: 5-40.

15. American Thoracic Society (ATS). Standardization of spirometry 1994 update. Am J Resp Crit Care 1995; 52: 1107-36.

16. Questionnaire on respiratory symptoms. Publication Group, Medical Research Council, 1976, London.

17. Das TK, Moutquin JM, Parent JG. Effect of cigarette smoking on maternal airway function during pregnancy. Am J Obstet Gynecol 1991; 165: 675-9.

18. Puranik BM, Kaore SB, Kurhade GA, Agrawal SD, Patwardhan SA, Kher JR. A longitudinal study of pulmonary function tests during pregnancy. Indian J Physiol Pharmacol 1994; 38: 129-32.

19. Mokkapatti R, Prasad EC, Fatima V, Fatima K. Ventilatory functions in pregnancy. Indian J Physiol Pharmacol 1991; 35: 237-40.

20. Gilroy RJ Jr, Lavietes MH, Loring SH, Manguara BT, Mead J. Respiratory mechanical effects of abdominal distension. J Appl Physiol 1985; 58: 1997-2003.

21. Gilroy RJ, Mangura BT, Lavietes MH. Rib cage and abdominal volume displacements in pregnancy. Am Rev Respir Dis 1988; 137: 668-72.

22. Knuttgen HG, Emerson K Jr. Physiological response to pregnancy at rest and during exercise. J Appl Physiol 1974; 36: 549-53.

23. Kociecki J. Spirographic evaluation of respiratory organs in pregnant women. Ann Acad Med Stetin 1970; 16: 48599.

24. Alaily AB, Carrol KB. Pulmonary ventilation in pregnancy. Br J Obstet Gynaecol 1978; 85: 518-24.

Address for correspondence:

Tomasz Sroczynski

Department of Physiology

Pomeranian Medical University

72, Powstancow Wlkp. St.

70-111 Szczecin

Poland

Phone: +48 914661611

Fax: +48914661612

E-mail: tomasz.sroczynski@ams.edu.pl 